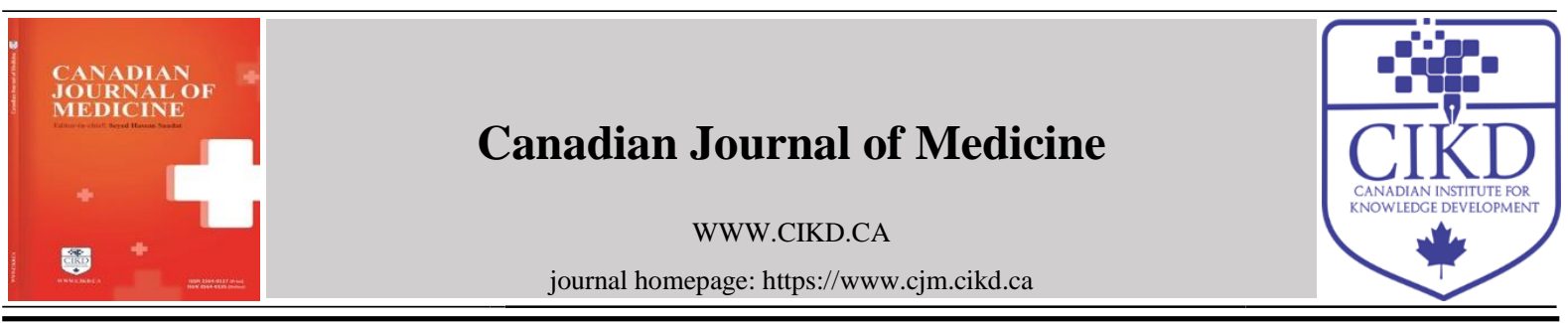

\title{
Cerebral Methanol Intoxication: A Case Report with Literature Review
}

\author{
Mehdi Mesri $^{1 *}$, Mohammad Javad Behzadnia ${ }^{2}$, Mohammad Nikpoor ${ }^{3}$, Ali Ghazvini ${ }^{4}$ \\ ${ }^{1}$ Forensic Medicine Specialist and Clinical Toxicology Fellowship, Baqiyatallah University of \\ Medical Sciences, Tehran, Iran \\ ${ }^{2}$ Department of Emergency Medicine, School of Medicine, Baqiyatallah University of Medical \\ Sciences, Tehran, Iran \\ ${ }^{3}$ Nephrology and Urology Research Center, Baqiyatallah University of Medical Sciences, Tehran \\ ${ }^{4}$ Trauma Research Center, Baqiyatallah University of Medical Sciences, Tehran, Iran
}

Keywords:

Methanol, Brain,

Hemorrhage, Imaging,

Emergency

\section{Received}

01 December 2021

Received in revised form

22 December 2021

Accepted

24 December 2021

*Correspondence:

m.mesri@savehums.ac.ir

\begin{abstract}
We report the case of a 24-year-old man admitted to the emergency room with a history of headache exacerbated. At the emergency room, he was unresponsive to drug or alcohol consumption. At this time, computed tomography (CT) did not detect the brain and abdomen lesions. At the intensive care unit (ICU), 6h later, he suddenly developed shallow respirations, followed by loss of consciousness, hypotension, and blurred vision. He was intubated immediately and underwent mechanical ventilation. Arterial blood gases and biochemical analyses indicated intense metabolic acidosis (Day1: $\mathrm{pH} 7.25, \mathrm{PCO} 249 \mathrm{mmHg}$, PO2 $65 \mathrm{mmHg}$, HCO3 $15 \mathrm{mmol} / \mathrm{L}$ and day 2, pH 7.32, PCO2 $45 \mathrm{mmHg}, \mathrm{PO} 260 \mathrm{mmHg}$, and $\mathrm{HCO} 3=19 \mathrm{mmol} / \mathrm{L}$ ) and elevated liver enzymes. The clinical diagnosis of toxic alcohol ingestion was based on the history, arterial blood gases results, and significant biochemical changes. In ICU, the patient underwent ethanol infusion and hemodialysis and the impression of methanol intoxication. He underwent redialysis with a minimal dose of heparin (5000 $\mathrm{IU} / \mathrm{mL}$ ). A second CT scan revealed basal ganglia ischemia, and an MRI scan exhibited clear abrasion and basal ganglia necrosis. Finally, he died due to severe methanol intoxication, but the probability of cerebral hemorrhage may be the cause of the patient death associated with heparin
\end{abstract}

(c)CIKD Publishing

\section{Background}

Methanol $(\mathrm{MeOH}, \mathrm{CH} 3 \mathrm{OH})$ intoxication causes serious toxicological concerns. Its adverse effects are associated with its metabolites (e.g., formic and lactic acid ), which are responsible for toxic due to cellular hypoxia and may cause a public health problem, metabolic damage, neurological dysfunction, cardiovascular disease, visual impairment, and even death [1-3]. In 
addition, it is involved in the agglomeration of formic acid inhibits cytochrome c oxidase activation in the mitochondria, resulting in damage of the basal ganglia, causing metabolic acidosis and visual disturbance [4,5].

In addition to symptoms containing headache, abdominal pain, nausea, vomiting, and loss of vision may appear several hours to days after exposure, elevated serum osmolal gap and anion gap metabolic acidosis can be evidence of its toxic presence [6,7].

On the other hand, the production of toxic metabolites by the enzymes alcohol dehydrogenase $(\mathrm{ADH})$ and aldehyde dehydrogenase (ALDH) can lead to bilateral necrosis of the central nervous system (CNS), which can be identified on computed tomography (CT) and magnetic resonance imaging (MRI) [8,9].

\section{Case Presentation}

A 24-year-old man presented to our emergency department because of a headache exacerbated at 3 am in June 2019. The emergency room physician eventually demands a CT scan for the patient (Figure 1). He did not exhibit any lesions on the CT scan of the head and abdomen. Initially, the patient showed no indication of medication and or alcohol consumption. Furthermore, the patient was admitted to the intensive care unit (ICU) at 9-11 am, and the possibility of alcohol intoxication was raised with a new history of blurred vision. Then, the patient rapidly deteriorates about 2 hours after admission to the ICU and develops respiratory distress (with quick, shallow respirations) and reduction of consciousness level. In parallel, regarding the shallow respiration, the patient was intubated immediately and underwent mechanical ventilation in the ICU. Subsequently, the advice of a nephrology and poisoning consultant were requested. 


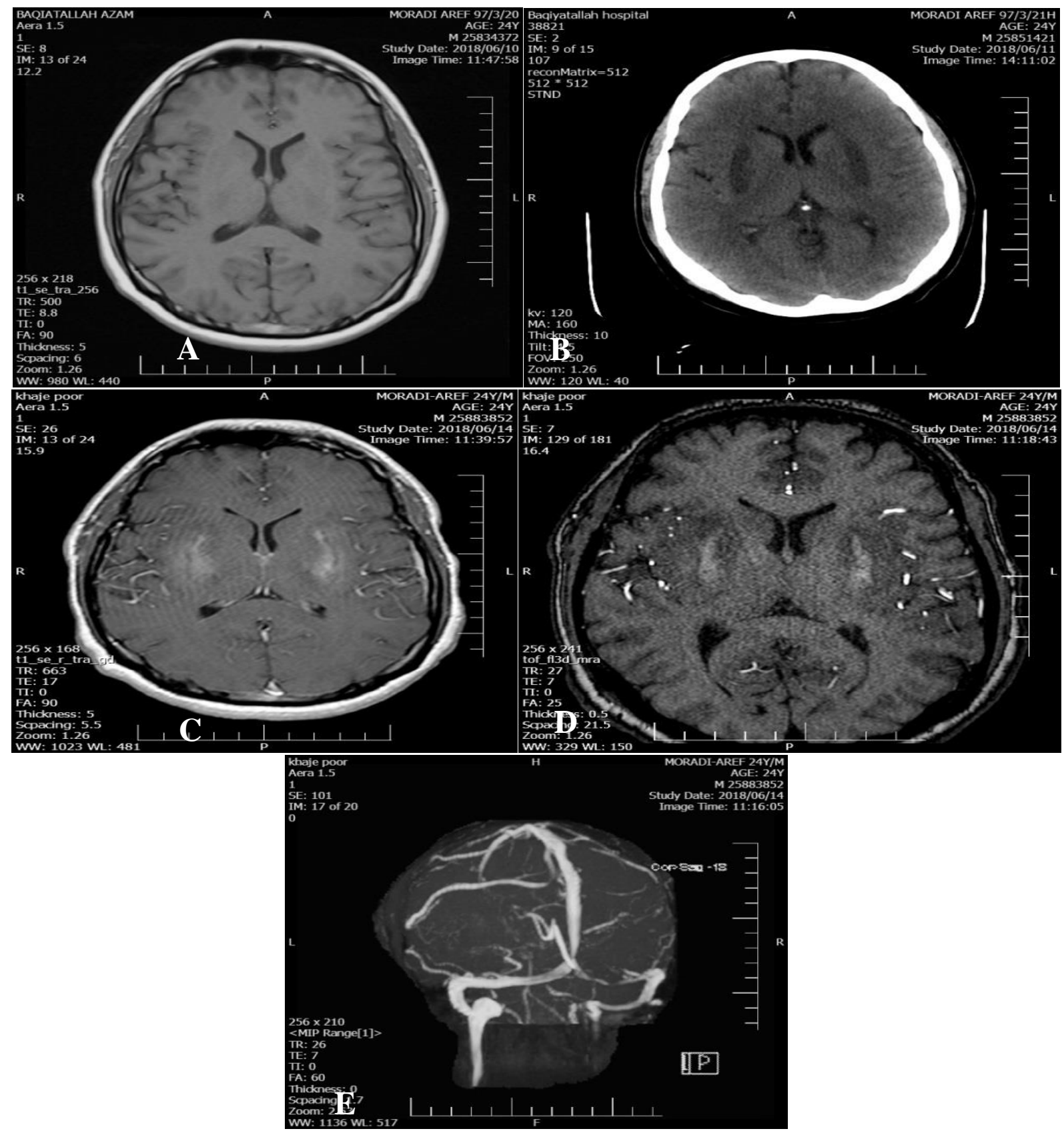

Figure 1. A: Brain MRI showed a normal pattern without any specific lesion on the $1^{\text {st }}$ day. B: Brain CT Scan of the patient revealed bilateral putamenal ischemia at day 2. C and D: Brian MRI with contrast revealed significant Putamenal necrosis at day 4. E: Brain angiography did not show any vascular abnormality at day 4.

The possibility of methanol poisoning was given by Toxicological analysis service due to the history of headache, hypotension and arterial blood gas (ABG) changes, and respiratory disorder, and he swiftly underwent emergency Shaldon catheter and then underwent dialysis for 4 hours. In the ward, the patient was hospitalized and other supportive actions were done for the patient. The serum ethanol and methanol levels were subsequently measured. Regarding the primary status of methanol level $(9 \mathrm{mg} / \mathrm{dl}$. The presence of metabolic acidosis and the status of bicarbonate therapy can be stated due to the patient's physiological situation at the sampling time. The Osmolol and Anion Gap gauges were unavailable, and the formula calculation did not help much. 
On the first day, initial ABG laboratory findings included $\mathrm{pH} 7.25, \mathrm{PCO}_{2} 49 \mathrm{mmHg}, \mathrm{PO}_{2} 65$ $\mathrm{mmHg}$, and $\mathrm{HCO}_{3} 15 \mathrm{mmol} / \mathrm{L}$. On the second day, $\mathrm{ABG}$ was also determined $\left(\mathrm{pH} 7.32, \mathrm{PCO}_{2}\right.$ $45 \mathrm{mmHg}, \mathrm{PO}_{2} 60 \mathrm{mmHg}$, and $\mathrm{HCO}_{3}=19 \mathrm{mmol} / \mathrm{L}$ ). Again the advice of the nephrology consultant recommended that the patient undergo redialysis with the minimal dose of heparin $(5000 \mathrm{IU} / \mathrm{mL}$ ) (Table 1). From day 3, his consciousness and respiratory status gradually recovered, he became alert, and his blurred vision extremely improved.

Table 1

The Biochemical Parameters of the Patient with Methanol Poisoning

\begin{tabular}{|c|c|c|c|c|}
\hline Variables & Day 1 & Day 2 & Day 3 & Day 4 \\
\hline $\mathrm{pH}$ & 7.25 & 7.32 & - & 7.46 \\
\hline $\mathrm{PCO}_{2}(\mathrm{mmHg})$ & 49 & 45 & - & 37 \\
\hline $\mathrm{PO}_{2}(\mathrm{mmHg})$ & 65 & 60 & - & 29 \\
\hline $\mathrm{HCO}_{3}(\mathrm{mEq} / \mathrm{L})$ & 15 & 19 & - & 27.6 \\
\hline $\mathrm{WBC} \times 10^{\wedge} 3 / \mu \mathrm{L}$ & 9.0 & 24.4 & 13.5 & 12.4 \\
\hline $\mathrm{RBC} \times 10^{\wedge} 6 / \mu \mathrm{L}$ & 5.42 & 5.53 & 4.66 & 3.81 \\
\hline Hemoglobin (g/dL) & 16.3 & 17.1 & 14.5 & 11.7 \\
\hline Hematocrit $\%$ & 45.6 & 44.7 & 37.4 & 33 \\
\hline MCV fl & 84.13 & 80.83 & 80.26 & 86.61 \\
\hline $\mathrm{MCH} \mathrm{Pg}$ & 30.07 & 30.92 & 31.12 & 30.71 \\
\hline MCHC g/dL & 35.75 & 38.26 & 88.77 & 35.45 \\
\hline Platelet (/uL) & 221 & 232 & 127 & 76 \\
\hline Sodium $(\mathrm{mEq} / \mathrm{L})$ & 135 & 133 & 138 & 135 \\
\hline Potassium (mEq/L) & 5.5 & 3.2 & 2.9 & 3.6 \\
\hline Calcium-Ca (mg/dL) & 7.5 & - & 8.3 & 0.8 \\
\hline Phosphorus-P (mg/dL) & 6.0 & - & - & 3.5 \\
\hline Magnesium (Mg) (mg/dL) & 2.9 & - & - & - \\
\hline Methanol mg/dL & 9 & - & - & 181 \\
\hline Prothrombin time (s) & 17.5 & 15.2 & - & - \\
\hline PTT.Patient time (s) & 50 & 127 & - & - \\
\hline Blood sugar (mg/dL) & 443 & 172 & 154 & 107 \\
\hline Blood Urea Nitrogen mg/dL & 21 & 34 & 33 & 10 \\
\hline Creatinine $\mathrm{mg} / \mathrm{dL}$ & 2.1 & 2.2 & 1.6 & 0.8 \\
\hline AST UI/L & 25 & - & 140 & 92 \\
\hline ALT UI/L & 28 & - & 71 & 60 \\
\hline CK-MB (ng/mL) & 8.29 & - & - & - \\
\hline Troponin I (ng/mL) & 0.016 & - & - & - \\
\hline CRP-quantitative (mg/L) & 5.3 & - & - & - \\
\hline creatine phosphokinase (CPK) U/L & 157 & - & - & 2821 \\
\hline Lactate dehydrogenase (LDH) U/L & 351 & - & - & \\
\hline Serum Amylase U/L & - & - & 236 & 49 \\
\hline Total Bilirubin (mg/dL) & - & - & 1.0 & 0.6 \\
\hline Direct Bilirubin(mg/dL) & - & - & 0.4 & 0.3 \\
\hline
\end{tabular}

On the third day, $\mathrm{ABG}$ status was not measured, and $\mathrm{ABG}$ measurement was then requested by the poisoning service, in addition to redialysis orders by one of the physicians. After the third dialysis, the status of consciousness gradually became confused. Finally, at the end of day 3, CT scans were impaired, and basal ganglia ischemia was reported. And the final MRI showed clearly abrasion and basal ganglia necrosis.

This point should be noticed that the hemodynamic status was well within three or four days of hospitalization. Only on the first day, he had severe acidosis, respiratory disorder, loss of consciousness, and hypotension, which elevated by improving ventilation and giving two vials of sodium bicarbonate 2 to $44 \mathrm{mEq} / \mathrm{kg}$ IV of blood pressure remained.

In the time of consciousness, the patient received $600 \mathrm{mg}$ of $\mathrm{N}$-acetylcysteine (NAC) (IV, 3 times daily) for 3 days, but NAC ( 2 g per $12 \mathrm{~h}$ ) and folic acid $(50 \mathrm{mg}$ of folic acid per $12 \mathrm{~h}$ for 3 days) was injected on the second day. Despite the continued intensive care of the patient and his treatment, unfortunately, he eventually died in ICU due to severe methanol intoxication.

In the patient's clinical record, the cause of death was respiratory failure related to methanol intoxication. Regarding ischemic necrosis, the probability of cerebral hemorrhage may cause 
the patient death. The therapeutic intervention was delayed; he was treated only with hemodialysis and a single dose of ethanol.

\section{Discussion and Conclusion}

The patients with $\mathrm{MeOH}$ intoxication presented to the emergency ward with multifarious complaints. Typical signs of $\mathrm{MeOH}$ intoxication included metabolic acidosis, central nervous system depression or sequelae, vision disturbances, or ocular changes caused by formic acid, a toxic metabolite of $\mathrm{MeOH}[8,10]$. Symptoms can typically include dizziness, headache, dyspnea, nausea, vomiting, abdominal pain, impaired sensorium, weakness, hardness of movement, and blurring vision [1, 2], as well as respiratory arrest [11], coma, and death in severe poisoning [6]. In parallel, we observed the symptoms such as headache, hypotension, respiratory disorder, and even blurred vision in the present case. The majority of the clinical abnormalities are the intensity of intoxication. The clinical outcomes correlate more with the acidosis level than the $\mathrm{MeOH}$ levels, and metabolic acidosis is likely due to formic acid and lactic acid agglomeration. All in all, these observations possibly could reflect the accumulation of the above metabolites [12,13]. Systemic effects are mostly due to metabolic acidosis resulting from formic acid reposition [14] as well as the ocular impairment is associated with the acidosis degree [11].

Based on pathogenesis mechanisms, methanol is metabolized to formaldehyde by alcohol dehydrogenase and then to formic acid with high toxicity (responsible for the systemic metabolic acidosis[the toxic effects and cause the increase of lactic acid]) by formaldehyde dehydrogenase in the hepatic using metabolic pathways. This conversion happens extremely fast, with a half-life of 1-2 minutes in humans [7, 10, 11, 15]. In addition, the CNS is very sensitive to formic acid toxicity, which inhibits some oxidase systems like cytochrome oxidase, and blocks adenosine triphosphate production (ATP) in mitochondria, resulting in axonal cell death and cellular hypoxia, lactic acid reposition or lactate formation, and elevated academia $[3,6,16]$. Regarding mechanisms mentioned, Zakharov et al. and Nurieva and Kotikova et al. reported that methanol poisoning could be associated with violent visual disturbance and basal ganglia damage [4, 17]. Our patient revealed blurred vision and basal ganglion necrosis in agreement with the above findings. Of course, the mechanism responsible for necrosis is unknown. Nevertheless, the above outcomes make methanol metabolites (such as formic acid and metabolic acidosis) better indicators of methanol toxicity when measured $48 \mathrm{~h}$ after $\mathrm{MeOH}$ ingestion and remedial intervention $[3,9,18]$.

Hemorrhage is one of the usual side effects of any anticoagulant, and heparin is the most common anticoagulation factor utilized for dialysis [19]. Many studies reported that heparinization in $\mathrm{MeOH}$ poisoned patients during hemodialysis may contribute to cerebral hemorrhagic complications in the necrotic areas of the brain and recommended a deleterious role of systemic anticoagulation during hemodialysis [19-23]. In contrast, Taheri et al . and Vyas et al. defined an unknown mechanism as main indicator of putaminal hemorrhage and brain necrosis in patients with $\mathrm{MeOH}$ toxicity [24, 25]. Furthermore, Aisa and Ballut and Zakharov et al. indicated no relationship of cerebral hemorrhage with systemic anticoagulation such as heparin during dialysis [26, 27]. Furthermore, McLean et al. and Ganguly et al. demonstrated that hemorrhagic brain lesions in the basal ganglia are due to the direct poisonous effect of formic acid in patients with $\mathrm{MeOH}$ poisoning [28, 29].

In summary, heparin could be associated with converting from basal ganglia necrosis to cerebral hemorrhage in ICU. It seems that heparin (ICU 5000 daily from day 2) may cause a brain hemorrhage. Nevertheless, there is a definite association between systemic 
anticoagulation (such as heparin) and cerebral hemorrhage in patients with $\mathrm{MeOH}$ intoxication as the cause of death in these patients?

On the other hand, optimal treatment of $\mathrm{MeOH}$ intoxication is historically difficult, but it requires primary accurate and fast diagnosis, and rapid initiation of effective therapy guarantees a better prognosis.

\section{Abbreviations}

$\mathrm{MeOH}=$ Methanol, $\mathrm{CT}=$ computed tomography, ICU =intensive care unit, IVH= intraventricular hemorrhage, $\mathrm{ATP}=$ adenosine triphosphate production, $\mathrm{NAC}=\mathrm{N}$ acetylcysteine, $\mathrm{NAC}=\mathrm{N}$-acetylcysteine, $\mathrm{ADH}=$ alcohol dehydrogenase, $\mathrm{ALDH}=$ aldehyde dehydrogenase, $\mathrm{CNS}=$ central nervous system , MRI= magnetic resonance imaging

\section{References}

[1] Dogan H, Yilmaz Karakus B, Serefoglu Cabuk K, Uzun O, Yenice H, et al. Transdermal spirit (Methanol) poisoning: A case report. Iran Red Crescent Med J. 2016; 18(11):e23767.

[2] Kraut JA. Approach to the treatment of methanol intoxication. Am J Kid Dis. 2016;68:161-167.

[3] Brahmi N, Blel Y, Abidi N, Kouraichi N, Thabet H, Abderrazek Hedhili A. Methanol poisoning in Tunisia: Report of 16 cases. Clinic Toxicol. 2006:717-720.

[4] Nurieva O, Kotikova K. Severe methanol poisoning with Supralethal serum formate concentration: A case report. Med Princ Pract. 2015;24:581-583.

[5] Liesivuori J, Savolainen H. Methanol and formic-acid toxicity - biochemical-mechanisms. Pharmacol Toxicol. 1991;69:157-163.

[6] Oguz AB, Gunalp M, Polat O, Genc S, Gurler S. Transdermal methanol intoxication. Arch Iran Med. 2019 Nov $1 ; 22(11): 671-672$.

[7] Ran M, Li Y, Zhang L, Wu W, Lin J, Liu Q, Ou S. Clinical features, treatment, and prognosis of acute methanol poisoning: experiences in an outbreak. Int. J Clin Exp Med. 2019;12(5):5938-5950.

[8] Dally AM. Fatal methanol intoxication - two exceptional cases.Toxichem Krimtech 2015;82(1):27.

[9] Kim HJ, Sunwoo MK, Lee JH, Choi YS, Kim DY. Methanol-induced encephalopathy: A case report. IMRI 2017;21:6164.

[10] Yoshizawa T, Kamijo Y, Fujita Y, Suzuki Y, Hanazawa T, Usui K . Mild manifestation of methanol poisoning half a day after massive ingestion of a fuel alcohol product containing 70\% ethanol and 30\% methanol: a case report. Acute Med Surg. 2018;5(3): 289-291.

[11] Shah S, Pandey V, Thakore N, Mehta I. Study of 63 cases of methyl alcohol poisoning (hooch tragedy in Ahmedabad). J Assoc Physicians India. 2012;60:34-36.

[12] Mcmartin KE, Ambre JJ, Tephly TR. Methanol poisoning inhuman subjects; Role of formic acid accumulation in metabolic acidosis. Amer J Med 1980;68:414-418.

[13] Sejersted DM, Jacobsen D, Vreb S. Letters to Editor: Methanol poisoning. Lancet 1981;2:1426.

[14] Ma Z, Jiang H, Wang J. Clinical analysis of severe visual loss caused by inhalational methanol poisoning in a chronic process with acute onset: a retrospective clinical analysis. BMC Ophthalmol. 2019;124.

[15] Yang CS, Tsai WJ, Lirng JF. Ocular manifestations and MRI findings in a case of methanol poisoning. Eye 2005;19:806809.

[16] Hizarci B, Erdogan C Transdermal methyl Derm Venereol. 2015;95(6):740-1. alcohol $\begin{array}{lll}\text { Karaaslan } & P, & \text { Unlukaplan } \\ \text { intoxication: } & \text { a } & \text { case }\end{array}$ A,
report.

[17] Zakharov S, Kurcova I, Navratil T, et al. Is the measurement of serum formate concentration useful in the diagnostics of acute methanol poisoning? A prospective study of 38 patients. Basic Clin Pharmacol Toxicol. 2015;116:445-451.

[18] Ferrari LA, Arado MG, Nardo CA, Giannuzzi L. Post-mortem analysis of formic acid disposition in acute methanol intoxication. Forens Sci Int. 2003;133: 152-158. 
[19] Hassanian-Moghaddam H, Bahrami-Motlagh H, Zamani N, Seyed Fazeli A, Behnam B. Intracranial Hemorrhage in Methanol Toxicity: Challenging the Probable Heparin Effect during Hemodialysis. J Res Pharm Pract. 2017;6(3):186189.

[20] Phang PT, Passerini L, Mielke B, Berendt R, King EG. Brain hemorrhage associated with methanol poisoning. Crit Care Med. 1988;16:137-40.

[21] Giudicissi Filho M, Holanda CV, Nader NA, Gomes SR, Bertolucci PH. Bilateral putaminal hemorrhage related to methanol poisoning: A complication of hemodialysis? Case report. Arq Neuropsiquiatr. 1995;53:485-7.

[22] Askar A, Al-Suwaida A. Methanol intoxication with brain hemorrhage: Catastrophic outcome of late presentation. Saudi J Kidney Dis Transpl. 2007;18(1):117-9.

[23] Moharamzadeh P, Rahmani F, Pouraghaei M, Ebrahimi Bakhtavar H, Mohammadzadeh Abachi E. Epidural Hematoma following hemodialysis in a methanol poisoned patient: A case report. Emergency. 2014;2(1):48-49.

[24] Taheri MS, Moghaddam HH, Moharamzad Y, Dadgari S, Nahvi V. The value of brain CT findings in acute methanol toxicity. Eur J Radiol. 2010;73:211-4.

[25] Vyas S, Kaur N, Sharma N, Singh P, Khandelwal N. Methanol poisoning. Neurol India. 2009;57:835-6.

[26] Aisa TM, Ballut OM. Methanol intoxication with cerebral hemorrhage. Neurosciences (Riyadh). 2016;21:275-7.

[27] Zakharov S, Kotikova K, Vaneckova M, Seidl Z, Nurieva O, Navratil T, et al. Acute methanol poisoning: Prevalence and predisposing factors of haemorrhagic and non-haemorrhagic brain lesions. Basic Clin Pharmacol Toxicol. 2016;119:22838.

[28] McLean DR, Jacobs H, Mielke BW. Methanol poisoning - a clinical and pathological-study. Ann Neurol. 1980;8:161-7.

[29] Ganguly G, Banerjee A, Mukherjee S, Das SK, Maity B. Bilateral basal ganglia haemorrhage-uncommon manifestation of methanol poisoning. J Assoc Physicians India. 1996;44: 834- 5.

\section{Ethics approval and consent to participate}

This case report was described in accordance with the ethical standards laid down in the "Declaration of Helsinki 1964".

\section{Consent for publication}

Written informed consent for publication of the case report was obtained from the patient's parents.

\section{Availability of data and materials}

All data supporting our findings are contained within the manuscript

\section{Competing interests}

The authors declare that they have no competing interests

\section{Funding}

The authors have not declared a specific grant for this research from any funding agency in public, commercial or not-for-profit sectors.

\section{Authors' contributions}

All authors participated in the literature review, designed the manuscript, revised the manuscript, and completed this case report. All authors read and approved the final manuscript

\section{Acknowledgements}

Not applicable. 